\title{
Perceptions of Air Quality and Sense of Place among Women in Northeast Hamilton, Ontario, Canada
}

\author{
Melissa Gallina \& Allison Williams \\ Correspondence: Melissa Gallina, McMaster University, Canada \\ Received: May 8, 2014 \\ Accepted: May 23, $2014 \quad$ Available online: June 2, 2014 \\ doi:10.11114/ijsss.v2i3.412 \\ URL: http://dx.doi.org/10.11114/ijsss.v2i3.412
}

\begin{abstract}
Research on environmental health risks suggests that public perceptions of risk may be greater than quantitative health risk assessments, especially amongst vulnerable groups such as women and immigrants. This study uses the environmental stress and coping framework to examine individual perceptions of air quality amongst Canadian-born and immigrant women in Northeast Hamilton, Ontario, Canada. Furthermore, the study aims to determine the influence of sense of place on local environmental perceptions. Quantitative survey results suggest that Canadian-born residents have a higher absolute value of sense of place than immigrants. Qualitative focus group discussions suggest that, compared to immigrant women, Canadian-born women may be more aware, knowledgeable and concerned about larger-scale air quality issues; however, the tension between economic and environmental needs hinders their sense of control. Bringing the quantitative and qualitative data together suggests that sense of place may inform environmental perceptions.
\end{abstract}

Keywords: Sense of Place, Environmental Perceptions, Immigrant, Women, Hamilton

\section{Introduction}

\subsection{Literature Review}

Poor air quality in Northeast Hamilton can be attributed to a combination of factors, including: industrial emissions; traffic emissions; and, temperature inversions resulting from proximity to Lake Ontario and the Niagara Escarpment (Buzzelli \& Jerrett, 2004; Adams et al., 2012). Past studies in Hamilton have shown a negative relationship between socio-economic status and exposure to air pollution (Jerrett et al., 2001; Buzzelli et al., 2003; Buzzelli \& Jerrett, 2004). Some evidence suggests that certain visible minority groups may also be disproportionately exposed (Buzzelli \& Jerrett, 2004).

Research on environmental health risks suggests that white males tend to rate risks lower than all other groups (white women and non-whites), providing a rationale for this research (Flynn et al., 1994; Finucane et al., 2000). According to the postmaterialist thesis, the environmental perceptions of immigrants might differ from that of the dominant social group (Lovelock et al., 2013). The postmaterialist thesis suggests that individuals from richer, more developed countries have higher levels of environmental concern than those from poorer, less developed countries (Inglehart, 1995; Lovelock et al., 2013). The postmaterialist thesis reasons that individuals residing in developing countries are preoccupied with meeting basic needs; and therefore are less concerned about the environment (Inglehart, 1995; Lovelock et al., 2013). However, it is suggested that immigrants from less developed countries may experience increased levels of environmental concern once they become settled in a more developed country (Inglehart, 1995; Lovelock et al., 2013). Furthermore, women exhibit greater concern for environment and health compared to men, due to their traditional role as caregivers (Stern et al., 1993; Momsen, 1999).

Past geographical studies have used the environmental stress and coping theory as a framework for examining individual perceptions and resulting coping strategies associated with environmental risk (Elliott et al., 1997; Wakefield et al., 2001). Within this theoretical approach, stress is defined as "the process by which environmental events or forces, called stressors, threaten an organism's existence and well-being and by which the organism responds to this threat" (Baum \& Singer, 1982, 15). Environmental pollution is recognized as a stressor (Shankardass, 2012). The environmental stress and coping theory involves three main components: perceptions or appraisals of the stressor; coping with the stressor; and, adapting to the stressor (Baum \& Singer, 1982; Bell \& Fisher, 1990). This study will focus on individual perceptions and chosen coping strategies related to air pollution. 
A number of factors have been found to influence individual perceptions of air quality including: knowledge and awareness (Crowe, 1968; Swan, 1970; Evans \& Jacobs, 1982; Bickerstaff \& Walker, 2001); perceived control and coping abilities (Baum \& Singer, 1982; James \& Eyles, 1999); concern and perception of risk (Baum \& Singer, 1982; Elliott et al., 1999; Bush et al., 2001); and, sense of place and place attachment (Kaltenborn, 1998; Bickerstaff \& Walker, 2001; Bush et al., 2001; Vaske \& Kobrin, 2001; Vorkinn \& Riese, 2001). Public knowledge of air pollution tends to be limited to suspected causes and observed effects, rather than knowledge about its actual composition (Evans \& Jacobs, 1982). However, individuals with a higher level of education or higher socioeconomic status are more likely to define air pollution in terms of its causal agents and complex nature (Crowe, 1968). Individual awareness of air pollution often results from sensory information such as, poor visibility, odours, or discoloration of property (Evans \& Jacobs, 1982; Bickerstaff \& Walker, 2001). Studies have shown that lower socioeconomic status groups tend to be less aware of air pollution (Swan, 1970).

Individuals with a strong sense of control feel that they can effectively cope with a stressor; therefore, perceived control is recognized as a mediator of stress (Baum \& Singer, 1982). Comparatively, individuals with a weak sense of control are less likely to take action against the stressor (Baum \& Singer, 1982). Studies have shown that, in general, individuals perceive low levels of control over the environment; this is especially true for those in vulnerable groups (Baum \& Singer, 1982; James \& Eyles, 1999). Evaluation of a stressor is dependent upon the perception of risk associated with the stressor (Baum \& Singer, 1982). Within the context of air pollution, public perceptions of risk may be greater than quantitative health risk assessments, or individuals may choose to disassociate themselves from apparent health risks (Elliott et al., 1999; Bush et al., 2001).

Coping with an environmental stressor can be either problem-focused or emotion-focused (Lazarus \& Folkman, 1984). Problem-focused strategies involve attempts to manipulate the relationship between the individual and the stressor by generating solutions and taking action, such as, forming a local citizen's group (Baum \& Singer, 1982; Lazarus \& Folkman, 1984; Wakefield et al., 2001). Examples of active coping mechanisms associated with air pollution include: seeking information or voicing complaints about air pollution; altering transportation behaviour or reducing outdoor activities during periods of high air pollution concentration (Lazarus \& Folkman, 1984). In contrast, emotion-focused strategies do not involve changing objective situations (Lazarus \& Folkman, 1984). Instead, individuals alter their internal environment, for example through avoidance or reassessing the situation as non-threatening, in order to lessen emotional distress (Lazarus \& Folkman, 1984; Baum \& Singer, 1982; Bell \& Fisher, 1990). For example, individuals may acknowledge a linkage between air pollution and health, but deny personal risk (Bickerstaff \& Walker, 2001).

Furthermore, this research explores whether perceptions of air quality and chosen coping strategies are informed by individual evaluations of sense of place (SoP). SoP has been described as: "the attitudes and feelings that individuals and groups hold vis-à-vis the geographical areas in which they live. It further commonly suggests intimate, personal and emotional relationships between self and place" (Wylie, 2009, 676). The physical environment is largely absent in SoP literature, providing further rationale for this study (Stedman, 2003). This research builds on earlier work, which found that immigrants in Hamilton had lower evaluations of SoP than their Canadian-born counterparts (Galling \& Williams, 2014). Lower evaluations of SoP amongst immigrant respondents may be attributed to: a 'disruption' of SoP during the immigration process; younger age distribution; and/or, lower median incomes (Gallina \& Williams, 2014).

Place attachment, a concept closely linked with SoP, has been related to environmental perceptions (Vaske \& Kobrin, 2001). Place attachment refers to "the affective link that people establish with specific settings, where they tend to remain and where they feel comfortable and safe" (Hernandez et al., 2007, 310). For example, a study conducted in Norway determined that residents with higher levels of place attachment were more likely to have negative attitudes towards development causing environmental harm (Vorkinn \& Riese, 2001). Kaltenborn (1998) suggests that individuals with a strong SoP are more committed to solving problems associated with local environmental issues. Conversely, studies have also identified a 'neighbourhood halo effect' where individuals are reluctant to acknowledge local pollution due to a strong commitment to place (Bickerstaff \& Walker, 2001; Bush et al., 2001; Vaske \& Kobrin, 2001). Furthermore, there is a gender dimension to SoP. Past research has shown that women are more "neighbourhood dependent" than men and tend to exhibit higher levels of place attachment (Hidalgo and Hernandez, 2001; Meegan and Mitchell, 2001).

This paper addresses the following research question: How do perceptions of air quality vary between immigrant and Canadian-born women living in Northeast Hamilton, and are they informed by SoP? There are three objectives associated with this research question: (1) to compare perceptions of air quality between immigrant and Canadian-born women; (2) to investigate coping strategies associated with poor air quality among these two groups; and, (3) to determine if evaluations of SoP inform perceptions of air quality. Following a description of the field site, the quantitative and qualitative methods employed in this research are outlined. Results are presented from the SoP survey and the focus group discussions. This is followed by a discussion and conclusions. 


\subsection{Area Description}

Hamilton is a mid-sized Canadian city located in Southwestern Ontario, approximately $75 \mathrm{~km}$ west of Toronto ( 2 \& Kitchen, 2012). In 2011, Hamilton's population was just under 520000 (Statistics Canada, 2012). The city, once a hub of industrial activity and steel production, has experienced economic restructuring in recent years, with development in the health and education sectors (Eby et al., 2012; 2 \& Kitchen, 2012). This reduction in manufacturing has resulted in economic decline within the city's inner core (Eby et al., 2012; 2 \& Kitchen, 2012). In 2005, Hamilton's poverty rate was $18 \%$, compared to $15 \%$ for the province as a whole (Mayo \& Fraser, 2009). However, poverty in Hamilton is unevenly distributed and income inequality continues to grow (Mayo \& Fraser, 2009; Mayo \& Pike, 2013). Residents living below the poverty line are concentrated among several neighbourhoods within the downtown core, with poverty rates reaching up to $46 \%$ (Mayo \& Pike, 2013). Certain vulnerable groups, such as women and recent immigrants, are more likely to live under the poverty line (Mayo \& Fraser, 2009).

\section{Methods}

This study contains qualitative analysis, supplemented by quantitative analysis. The methods and results are discussed in chronological order, beginning with a description of the quantitative methods. A more in-depth quantitative analysis is provided in the earlier work (Gallina \& Williams, 2014).

\subsection{Quantitative}

Data for this project was obtained from a household-based telephone survey conducted in Hamilton during the summer of 2012 ( $n=716$ ), as part of a larger quality of life study funded by the Social Sciences and Humanities Research Council of Canada (SSHRC). The response rate for the larger survey, which included three Canadian cities, was 23\%; households within each of the cities were selected randomly. The survey respondents were split between immigrants (those not born in Canada) and Canadian-born residents; approximately 60\% of survey respondents were born outside of Canada. Approximately $60 \%$ of the respondents were female and $40 \%$ were male. Sample size, for both the number of households and the size of the immigrant population, were informed by the 2006 census; households were randomly selected to participate in the survey.

Participants were asked to complete a 16-item SoP scale, developed by Williams et al. (2010) (Appendix A). The survey evaluates individual perceptions of four SoP factors: neighbourhood rootedness; neighbourhood sentiment; neighbours; and, environment and health using a 5-point likert scale. The SoP scale was developed from a larger survey of 46 items shown to influence neighbourhood SoP; Williams et al., (2010) selected the 16 most influential items, which were then separated into four factors using a principal components analysis (a more thorough description of this analysis is provided by Williams et al., 2010). An established SoP formula (Williams et al., 2010) was employed to calculate individual evaluations of SoP (Equation 1). Due to the nature of the SoP formula, any records with a missing response to one of the sixteen SoP questions were eliminated from the analysis; a total of 631 responses were used in the analysis. Further information on the SoP scale and its analysis can be found in the earlier work (Gallina \& Williams, 2014).

$$
\text { Neighbourhood SoP }=[((20-\Sigma \text { Factor } 1)+(20-\Sigma \text { Factor } 2)+(20-\text { EFactor } 3)+(20-\Sigma \text { Factor } 4)) / 64] \times 100
$$

Individual evaluations of SoP were used to calculate mean SoP values for: (1) Canadian-born women; (2) immigrant women; (3) Canadian-born men; and, (4) immigrant men. A total of 631 telephone survey responses were included in the analysis. SAS statistical software was used to analyze the telephone survey data. The resulting SoP values were triangulated with the qualitative results of this study. Qualitative focus group data was used to provide depth to the discussion of SoP within the quantitative data.

\subsection{Qualitative}

Two focus groups were conducted during the summer of $2013(n=2)$. The first focus group was comprised of Canadian-born women $(\mathrm{n}=8)$; the second group was comprised of immigrant women from a variety of ethnic backgrounds $(\mathrm{n}=8)$. The majority of immigrant women originated from the Middle East and Africa. Recruitment of the focus group participants was completed with the assistance of local community organizations. Participants were selected based on: their gender (female); immigrant status; and neighbourhood of residence (Northeast Hamilton). For the purpose of this study, immigrants are defined as those who currently reside in Canada but were born outside of the country. In order to participate in this study, individuals were required to have a working knowledge of the English language; therefore, translation services were not provided. Ethics approval was obtained via the McMaster University Research Ethics Board in 2013. 
Table 1. Socio-demographic characteristics of focus group participants

\begin{tabular}{|c|c|c|c|c|c|c|}
\hline Participant & $\begin{array}{c}\text { Length of } \\
\text { Residence } \\
\text { (neighbourhood) }\end{array}$ & $\begin{array}{l}\text { Length of } \\
\text { Residence } \\
\text { (address) }\end{array}$ & Household & $\begin{array}{c}\text { Age } \\
\text { Category }\end{array}$ & $\begin{array}{l}\text { Length of } \\
\text { Residence } \\
\text { (Canada) }\end{array}$ & $\begin{array}{c}\text { Income } \\
\text { Category }\end{array}$ \\
\hline \multicolumn{7}{|c|}{ A) Canadian-born (CB) } \\
\hline CB-A & $1-5$ years & $1-5$ years & Own & $45-54$ & NA & $\$ 100000+$ \\
\hline CB-B & $5-10$ years & $5-10$ years & Rent & $25-34$ & NA & $\$ 20000-\$ 39999$ \\
\hline $\mathrm{CB}-\mathrm{C}$ & $5-10$ years & $1-5$ years & Own & $35-44$ & NA & Less than $\$ 20000$ \\
\hline CB-D & $5-10$ years & $5-10$ years & Own & $25-34$ & NA & $\$ 60000-\$ 79999$ \\
\hline CB-E & $1-5$ years & $1-5$ years & Rent & $45-54$ & NA & $\$ 40000-\$ 59999$ \\
\hline $\mathrm{CB}-\mathrm{F}$ & Don't know & Less than 1 year & Rent & $45-54$ & NA & $\$ 20000-\$ 39999$ \\
\hline CB-G & Don't know & Less than 1 year & Rent & $18-24$ & NA & Less than $\$ 20000$ \\
\hline $\mathrm{CB}-\mathrm{H}$ & Over 10 years & Less than 1 year & Rent & $25-34$ & NA & $\$ 20000-\$ 39999$ \\
\hline \multicolumn{7}{|c|}{ B) Immigrant (IM) } \\
\hline IM-A & $5-10$ years & $5-10$ years & Rent & $35-44$ & Over 10 years & Less than $\$ 20000$ \\
\hline IM-B & $1-5$ years & Less than 1 year & Rent & $35-44$ & $1-5$ years & Less than $\$ 20000$ \\
\hline IM-C & $1-5$ years & $*$ & Rent & $25-34$ & $1-5$ years & $*$ \\
\hline IM-D & $1-5$ years & Less than 1 year & Rent & $45-54$ & $1-5$ years & Less than $\$ 20000$ \\
\hline IM-E & $1-5$ years & Less than 1 year & Rent & $25-34$ & $1-5$ years & Less than $\$ 20000$ \\
\hline IM-F & Over 10 years & Over 10 years & Rent & $45-54$ & Over 10 years & Less than $\$ 20000$ \\
\hline IM-G & $5-10$ years & $1-5$ years & Rent & $35-44$ & $5-10$ years & Less than $\$ 20000$ \\
\hline IM-H & $*$ & $*$ & $*$ & $*$ & $*$ & $*$ \\
\hline
\end{tabular}

*Did not provide demographic information

Table 1 contains further socio-demographic information of the research participants. Participants discussed their perceptions of neighbourhood air quality and neighbourhood SoP during the focus group sessions.

Focus group questions were developed based on a review of the academic literature specific to: environmental stress and coping theory; and, SoP. These questions, which were vetted by key informants (e.g. community development workers, environment $\&$ health workers, etc.), were used as the basis for thematic codes. Nearing the end of each session, participants began to repeat earlier ideas and themes, indicating that saturation was reached. Focus groups were audio recorded and transcribed verbatim. All research participants were given the opportunity to verify the transcripts prior to analysis. NVIVO 9 was used to thematically code (Hay, 2010) the transcripts for: awareness of air quality; knowledge of air quality; concerns/risk perception; perceived control; coping mechanisms; and, neighbourhood perceptions.

\section{Results}

\subsection{Quantitative}

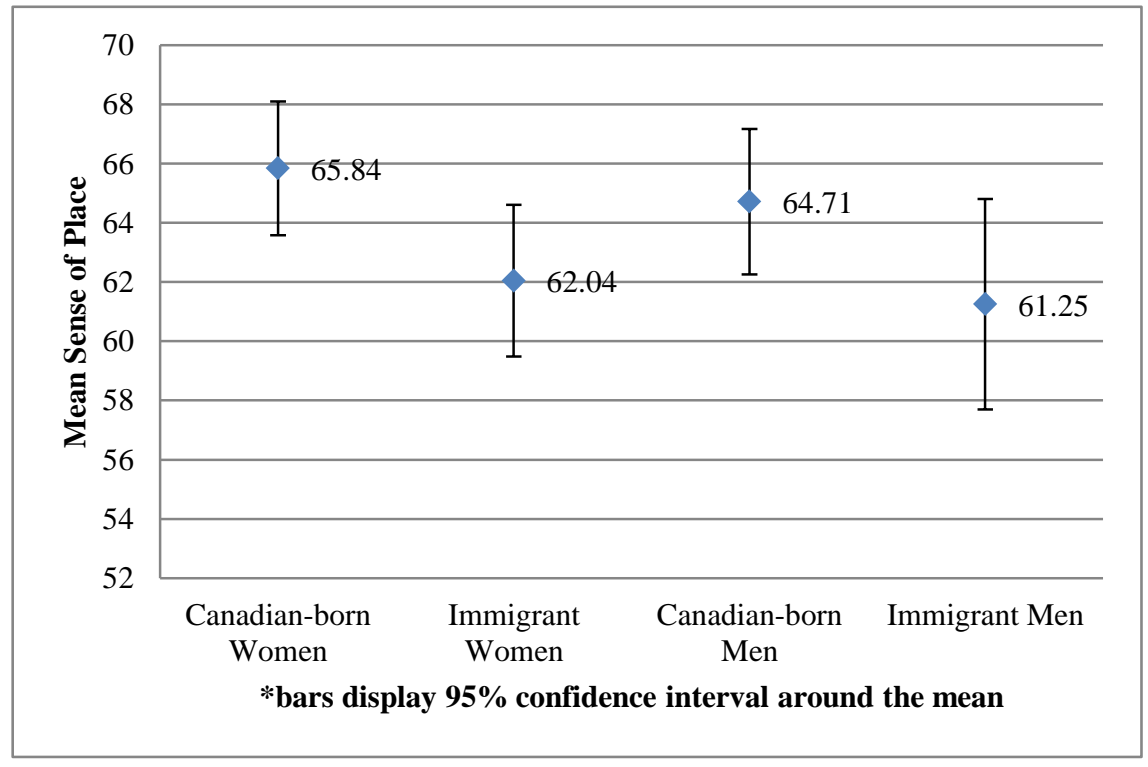

Figure 1. Sense of Place in Hamilton, Ontario: Telephone Survey $(n=631)$ 
Figure 1 shows the mean SoP values and 95\% confidence intervals. Values closer to 100 indicate more positive evaluations of SoP. Mean SoP values are as follows: Canadian-born women 65.84 (63.58-68.09); immigrant women 62.04 (59.49-64.60); Canadian-born men 64.71 (62.25-67.17); and, immigrant men 61.25 (57.69-64.80). None of the means are significantly different at the $95 \%$ confidence level. Though not statistically significant, the absolute value of SoP for Canadian-born women is higher than that of their immigrant counterparts; this result agrees with the results published in earlier work (Williams and Kitchen, 2012; Gallina \& Williams, 2014). In addition, both groups of women had higher absolute values of SoP than their male counterparts.

\subsection{Qualitative}

\subsubsection{Awareness of Air Quality}

Overall, the Canadian-born women are more aware of air quality issues in their neighbourhood, whereas the immigrant women require much more probing. Canadian-born women display their awareness of air quality through the discussion of sensory cues. For example, a Canadian-born participant comments on the dust from air pollution, and highlights the persistence of the issue:

$C B$-D: "I was going to comment on the windows thing, I've noticed that where the window meets the frame, there's just a little crack of air and that's where I get a nice little black line. And it's really interesting because I can clean that and then that line's there again in a day or two."

A second Canadian-born participant acknowledges the unpleasant odour associated with local industry:

$C B-F$ : "And then you add the soy plants in, and the stench coming from Dofasco, and you've got one heck of an odour in the air."

Canadian-born women frequently mention such sights and smells, which are often attributed to industrial processes. However, only one participant among the immigrant women's group mentioned a smell associated with industry:

IM-B: “...there's some smell from I think the companies and if you go outside and around in the morning there's some smell outside."

Participants tend to employ comparative techniques when describing their experiences with air quality. Canadian-born women compare their neighbourhood's air quality to other areas of Hamilton, Ontario, and Canada. However, immigrant women compare air quality to that of their home country. Individual awareness of air quality issues appears to be impacted by one's lived experience, as demonstrated below. For example, a Canadian-born participant compares the air quality in Hamilton to that of Sudbury:

CB-F: "I lived in Sudbury for 4 years... and the air there is just phenomenal, like you don't get the... there's just no factories to make the pollution up there, and I notice now, and I never noticed it living in Hamilton my whole life, you come over the Skyway and there's a particular odour [agreement], and it's that smell of the steel city. And you don't get that... I didn't notice it for so long... you live out of the city for so long where the air is so pure and clean and you come back to visit and it's like... it's gagging almost... you get used to it after time, you don't notice it, but you leave and come back and it's... for me anyways..."

An immigrant participant compares the air quality in Canada with her home country in the Middle East:

IM-E: "For us, like we found no, here is better. We can't compare like... because the war, yea it's better, because they causes more pollution than Canada."

In summary, Canadian-born women may be more aware of large-scale air quality issues in Hamilton and their neighbourhood specifically. Canadian women are more likely to acknowledge problems with air quality in their neighbourhood and identified industry as the cause of the pollution. Perceptions of air quality seem to be informed by past lived experiences, with Canadian-born individuals being more critical than immigrant participants with respect to air quality issues in Hamilton.

\subsubsection{Knowledge of Air Quality}

Similarly, the Canadian-born women may be more knowledgeable about the large-scale sources of air pollution. Canadian-born women identify industry as the source of air pollution, as displayed below. In comparison, immigrants tend to focus on individual agents, such as cigarette smokers producing second-hand smoke. A Canadian-born woman identifies local sources of air pollution:

$C B-F$ : “...we've got the air that comes from Dofasco [steel manufacturing plant] plus from the soy plants this way, plus right across the street from us they clean the machines that run at Dofasco, so we get like black stuff flying around in the air, so it's pretty, pretty nasty."

Immigrant participants do not feel that air pollution was a large problem in the neighbourhood. The immigrant women 
feel that second-hand smoke was a more pressing issue:

IM-C: "The pollution is good, for me too it's good. The problem is just those people when they are smoking."

It can be concluded that both Canadian-born and immigrant women have some knowledge of air quality issues; however, the scale of this knowledge is quite different. Canadian-born women recognize industry as the large-scale source of air pollution, whereas immigrants focus on more immediate, individual causes of environmental pollution.

\subsubsection{Concern/Risk Associated with Air Quality}

Canadian-born women are quite concerned about the health effects associated with poor air quality. Participants mention their own experiences, as well as the health conditions experienced by their children. For example, a Canadian-born woman attributes her daughter's health condition to poor neighbourhood air quality:

CB-F: "It bothers me as well, my 5-year-old has just acquired asthma, she's just been diagnosed with it, so... I can only think that it has happened because of what's going on in the air."

The immigrant women are not concerned about the negative health impacts of air pollution in the same capacity as their Canadian-born counterparts. Immigrant women were found to be much more concerned about other environmental health hazards, such as second-hand smoke. The following quotes demonstrate immigrant women's concern surrounding second hand smoke:

IM-D: "Well the people smoking, the smell of the drugs, you know the people cannot take that. And the kids too, if you have problem of the health. It's so hard."

IM-B: "Yea, because when they do the smoking, they stand outside at 2 AM in the morning, even to sleep is dangerous for us..."

Canadian-born women are also more knowledgeable of the specific health effects associated with air pollution, as depicted in the following section. The immigrant women are aware of the negative health effects associated with poor air quality on a smaller scale (i.e. second-hand smoke), although they do not discuss the health impacts associated with larger scale industrial pollution. It should be noted that not all participants reported negative health impacts associated with air quality.

\subsubsection{Perceived Control over Air Quality}

Canadian-born women argue that shutting down industry is not a viable solution to improve air quality, despite concern over industrial pollution. These women are familiar with Hamilton's economic difficulties and are worried about further job loss. There is also a sense of apathy among the Canadian-born women, given their acknowledgement of the legacy of industry in Hamilton. A Canadian-born participant highlights the tension between environment and economy:

CB-A: "Well, you think of how many people have lost jobs already, and like [Participant] said it's a steel town so like people are already struggling in the area so we take away more jobs and more employment, then what's left?"

The following quotes from Canadian women demonstrate the lack of control associated with Hamilton's industrial legacy:

$C B-G$ : "We won't be able to [improve air quality], until they move the factories, which will never happen."

$C B$-B: "I don't see a problem with it... I mean there is a lot of particles in the air, but what are we going to do about it, it's an industrial town so..."

Canadian-born women are interested in collectively making existing industry cleaner, although their individual perceived control is lacking. A Canadian-born woman proposed community organization as a potential solution:

$C B$-D: "I think what I was getting at more is the sense of having more people in sort of the, an association, a bigger body of people, so that when we go to the City of Hamilton and say, you know we've got 500 folks that meet once a month... and this is a concern for us, for 500... it carries some weight."

In comparison, the immigrant women do not feel a sense of control over their immediate environment. Therefore, it is unlikely that they would feel a sense of control over large-scale environmental concerns, such as air quality. For example, the following quote displays the lack of control over exposure to second-hand smoke:

IM-D: "You cannot stop the life of somebody... if they are smoking now you cannot say to stop to smoke."

Overall, it can be seen that immigrant women have a very weak sense of control over their neighbourhood air quality. The Canadian-born women have a comparatively stronger sense of control; however they recognize Hamilton's industrial legacy and the economic consequences associated with action. 


\subsubsection{Neighbourhood Perceptions}

Both groups of women appear to be satisfied with their neighbourhood, mentioning safety, convenience, and services as important factors. For example, a Canadian-born participant explains that she is proud to live in the neighbourhood due to the number of resources available:

CB-F: "So that tells you, like the area is slowly up and coming and I would say that I'm fairly proud of the neighbourhood ... with the community centres that we have and the resources for the people in the community, how close we are, the barbeques at the park where the whole neighbourhood's invited. You can live as far as Sherman and be able to come over this way. You know it's a nice thing to be part of a neighbourhood that has so many resources."

An immigrant participant highlights the importance of neighbourhood safety:

IM-E: "Yea, the safety and the community centre here."

The Canadian-born women seem fairly connected with their neighbours, despite issues with transience. The immigrant women are very connected within their ethnic communities, but not as connected with the Canadian population as a whole. A Canadian-born woman describes her close connections within the neighbourhood:

$C B-F$ : "And, you know we kind of watch out for each other and keep an eye, and you know who's coming on the street, you know the regular vehicles that drive up and down so if you see a vehicle that you don't know..."

A second Canadian-born participant describes transiency as a barrier to forming neighbourhood connections:

CB-D: "I wouldn't have a clue about the names of any of my neighbours... 'Cause of the transient nature of the building I'm in."

The following quote shows a lack of connection between the immigrant women and Canadian-born population:

\section{IM-A: "So many years I am in Canada, I don't have any Canadian friend."}

In summary, both groups have generally positive perceptions of their neighbourhood. However, both groups mention issues with neighbourhood connectedness. This was especially prevalent within the immigrant women's focus group, highlighting a lack of connection with Canadian-born individuals.

\subsubsection{Coping Mechanisms}

Both the Canadian-born and immigrant groups tend to employ problem-focused coping in response to their environmental perceptions. Coping mechanisms are often changes in individual behaviours, rather than reporting to higher authorities. A Canadian-born woman explains how she painted her house to cope with air quality issues:

CB-A: "And it's just the dust, like the front of my house, that's why I painted it green. When I first moved there it was white and stuff like that and then I was done. And I have OCD [obsessive compulsive disorder] so I like to clean and I just, I quit, I couldn't do it, I couldn't keep up [laughter]."

An immigrant participant alters her behaviour in response to poor air quality:

IM-D: "We choose the place where to sit if the smell is at the front of the house, we choose to go in the back."

A number of participants in each group indicate that they had taken more proactive coping approaches by reporting to higher authorities; however, behaviour changes are much more prevalent. Three of the Canadian-born women acknowledge reporting air quality issues to the local government (bylaws), while one immigrant women reports air quality issues to her landlord.

\section{Discussion}

Overall, the focus group discussions suggest that Canadian-born women may be more knowledgeable and aware of large-scale air quality issues in their neighbourhood. Furthermore, the Canadian-born women appear to be more concerned about air pollution and associated health impacts. Immigrant women were likely unaware of large-scale air quality issues due to their focus on more immediate environmental concerns. The majority of immigrant participants have low incomes, as shown in Table 1. Therefore, it can be reasoned that these individuals are also preoccupied with meeting basic needs. These findings support previous research, which suggested that individuals with low socioeconomic status are less likely to be aware of air quality and associated issues (Swan, 1970). Furthermore, these results support the postmaterialist thesis for environmental concern (Inglehart, 1995; Lovelock et al., 2013). It should also be noted that immigrant women compared the air quality in Canada to that of their home country, with some women acknowledging that the air is cleaner in Canada. The immigrant women might not recognize air quality as problematic in Canada since air quality issues are more salient in their home country (Schultz et al., 2000).

Both groups tended to employ problem-focused coping mechanisms. In both cases, these mechanisms tended to be reactive (i.e. altering individual behaviours) rather than preventative (i.e. taking action to address the source of 
pollution). It can be argued that their motivations for these actions differ, though both groups of women used similar coping mechanisms. It can be reasoned that immigrants are unaware of the sources of air pollution (i.e. industry) and thus cannot take preventative action. In comparison, the Canadian-born women are knowledgeable about the sources of pollution; however they are wary of the economic consequences associated with preventative action.

Bringing the qualitative and quantitative analyses, it appears that individuals with a higher SoP (i.e. Canadian-born respondents) may be more aware, knowledgeable, and concerned about higher-level environmental issues in their neighbourhood (i.e. air quality). Based on this finding, it may be suggested that SoP informs environmental perceptions. This is in keeping with the known evidence described above, with respect to both research on the postmaterialist thesis (where it is suggested that immigrants have lower levels of environmental concern when compared to native residents) and SoP (where, again, immigrants are found to have lower evaluations when compared to native residents).

Gallina and Williams (2014) suggest that increases in length of neighbourhood residence, median income, and age distribution would lead to stronger feelings of place amongst immigrant respondents. Therefore, assuming that immigrants follow the same trend as their Canadian-born counterparts, it may be expected that one would see an associated increase in environmental awareness, knowledge, and concern amongst immigrants if their SoP evaluations improve. This may translate into an increased commitment to address local environmental issues, as suggested by Kaltenborn (1998). Conversely, it is feasible that this could be a reciprocal relationship, where environmental perceptions also inform SoP. This relationship could be the focus of further research.

\section{Conclusion}

This study addressed three research objectives: (1) to compare perceptions of air quality between immigrant and Canadian-born women; (2) to investigate coping strategies associated with poor air quality among these two groups; and, (3) to determine if evaluations of SoP inform perceptions of air quality. Canadian-born women had higher evaluations of SoP than immigrant women. Differences in air quality perceptions across the two sample populations may be attributed to: lower socioeconomic status among immigrant women; comparative views of air quality; and, relative variation in levels of environmental concern across countries (i.e. country of origin versus country of residence). It is concluded that SoP and environmental perceptions might inform one another in a reciprocal manner; however, it is likely that there are other factors that shape this relationship.

There are a number of limitations to this study. One limitation of the study is that the focus groups were conducted in different neighbourhood areas due to difficulties with recruitment. The Canadian-born women were a more accessible population; a second neighbourhood was added to the recruitment strategy in order to reach the immigrant population, there may be other contextual factors influencing individual perceptions, even though the neighbourhood were near one another and similarly impacted by air pollution sources. It is recognized that those who have lived in Canada for a longer period of time might have different perceptions than those newly arriving in Canada. For the purposes of this study, immigrants are not sorted based on length of residence; however, it is noted that the majority of immigrants have lived in Canada for less than 10 years (Table 1).

The respondents involved in the quantitative analysis were split between both genders; however, the focus groups involved only women. Originally, the researcher attempted to recruit both men and women for the focus groups; however, the male population was much more difficult to reach. As suggested in previous research, women may be more interested and concerned about the natural environmental and the potential impacts on their family (Stern et al., 1993; Momsen, 1999). Nevertheless, it is recognized that the results of this research are unique to the female population. Finally, it is very likely that emotion-focused strategies were not discussed in the focus group, possibly due to the lack of familiarity and comfort with the other participants.

Greater emphasis is needed on immigrants' environmental education and the relationship between environmental issues and human health so that they may cope with exposures accordingly. It is noted that, within the Canadian-born focus group, women acknowledged that when addressing local environmental issues, there is "power in numbers", implying that there is an increased sense of control over such issues when working as a group, when compared to individuals themselves. Bringing this idea together with the recommendations above, it is suggested that Canadian-born individuals actively include immigrants in such efforts. The inclusion of immigrants in such efforts not only increases awareness of environmental issues, but may also increase immigrant commitment to place. Furthermore, the immigrants would add a unique perspective to community efforts, making such a proposition mutually beneficial. Further research could explore the motivations for chosen coping mechanisms, whether problem-focused (reactive or preventative) or emotion-focused, as mentioned above. Further research may also compare immigrants' environmental perceptions based on their country of origin.

\section{Acknowledgements}

The authors would like to thank the research participants and the community members who made this research possible: 
Ted Hodkinson, The Eva Rothwell Resource Centre, and, The Keith Neighbourhood Hub; David Derbyshire, The McQuesten Community Centre, and, The McQuesten Planning Team; and, Mission Services of Hamilton. The authors would also like to recognize the entire project team for their support: Nazeem Muhajarine, Bruce Newbold, James Randall, and Kathleen Wilson.

This study was supported by the Social Sciences and Humanities Research Council of Canada (SSHRC), SSHRC Immigration and the Metropolis (No. 808-2011-0005).

\section{References}

Adams, M. D., DeLuca, P. F., Corr, D., \& Kanaroglou, P. S. (2012). Mobile air monitoring: Measuring change in air quality in the city of Hamilton, 2005-2010. Social Indicators Research, 108(2), 351-364. http://dx.doi.org/10.1007/s11205-012-0061-5

Baum, A., \& Singer, J. E. (1982). Environment and health. Hillsdale, N.J.: L. Erlbaum Associates.

Bell, P. A., \& Fisher, J. D. (1990). Environmental psychology ( $3^{\text {rd }}$ ed.). Fort Worth: Holt Rinehart and Winston.

Bickerstaff, K., \& Walker, G. (2001). Public understandings of air pollution: The 'localisation' of environmental risk. Global Environmental Change, 11(2), 133-145. http://dx.doi.org/10.1016/S0959-3780(00)00063-7

Bush, J., Moffatt, S., \& Dunn, C. (2001). 'Even the birds round here cough': Stigma, air pollution and health in Teesside. Health \& Place, 7(1), 47-56. http://dx.doi.org/10.1016/S1353-8292(00)00037-X

Buzzelli, M., \& Jerrett, M. (2004). Racial gradients of ambient air pollution exposure in Hamilton, Canada. Environment and Planning, 36, 1855-1876. http://dx.doi.org/10.1068/a36151

Buzzelli, M., Jerrett, M., Burnett, R., \& Finklestein, N. (2003). Spatiotemporal perspectives on air pollution and environmental justice in Hamilton, Canada, 1985-1996. Annals of the Association of American Geographers, 93(3), 557-573. http://dx.doi.org/10.1111/1467-8306.9303003

Crowe, M. J. (1968). Toward a "Definitional model" of public perceptions of air pollution. Journal of the Air Pollution Control Association, 18(3), 154-157. http://dx.doi.org/10.1080/00022470.1968.10469106

Eby, J., Kitchen, P., \& Williams, A. (2012). Perceptions of quality life in Hamilton's neighbourhood hubs: A qualitative analysis. Social Indicators Research, 108(2), 299-315. http://dx.doi.org/10.1007/s11205-012-0067-z

Elliott, S., Cole, D., Krueger, P., Voorberg, N., \& Wakefield, S. (1999). The power of perception: Health risk attributed to air pollution in an urban industrial neighbourhood. Risk Analysis, 19(4), 621-634. http://dx.doi.org/10.1111/j.1539-6924.1999.tb00433.x

Elliott, S. J., Taylor, S. M., Hampson, C., Dunn, J., Eyles, J., Walter, S., \& Streiner, D. (1997). 'It's not because you like it any better...': Residents' reappraisal of a landfill site. Journal of Environmental Psychology, 17(3), $229-241$. http://dx.doi.org/10.1006/jevp.1997.0055

Evans, G. W., \& Jacobs, S. V. (1982). Air pollution and human behavior. In G. W. Evans (Ed.), (pp. 105-132). Cambridge: Cambridge University Press.

Finucane, M. L., Slovic, P., Mertz, C. K., Flynn, J., \& Satterfield, T. A. (2000). Gender, race, and perceived risk: The 'white male' effect. Health, Risk \& Society, 2(2), 159-172. http://dx.doi.org/10.1080/713670162

Flynn, J., Slovic, P., \& Mertz, C. K. (1994). Gender, race, and perception of environmental health risks. Risk Analysis, 14(6), 1101-1108. http://dx.doi.org/10.1111/j.1539-6924.1994.tb00082.x

Gallina, M., \& Williams, A. (2014) Variations in Sense of Place across Immigrant Status and Gender in Hamilton, Ontario; Saskatoon, Saskatchewan; and, Charlottetown, Prince Edward Island, Canada. Social Indicators Research, DOI: $10.1007 / \mathrm{s} 11205-014-0636-4$. http://dx.doi.org/10.1007/s11205-014-0636-4

Hay, I. (2010). Qualitative Research Methods in Human Geography (3rd ed.). New York, NY: Oxford University Press.

Hernández, B., Carmen Hidalgo, M., Salazar-Laplace, M. E., \& Hess, S. (2007). Place attachment and place identity in natives and non-natives. Journal of Environmental Psychology, 27(4), 310-319. http://dx.doi.org/10.1016/j.jenvp.2007.06.003

Hidalgo, M. C., \& Hernandez, B. (2001). Place attachment: Conceptual and empirical questions. Journal of Environmental Psychology, 21(3), 273-281. http://dx.doi.org/10.1006/jevp.2001.0221

Inglehart, R. (1995). Public support for environmental protection: Objective problems and subjective values in 43 societies. PS: Political Science and Politics, 28(1), 57-72. http://dx.doi.org/10.1017/S1049096500056080

James, J., \& Eyles, J. (1999). Perceiving and representing both health and the environment: An exploratory 
investigation. Qualitative Health Research, 9(1), 86-104. http://dx.doi.org/10.1177/104973299129121712

Jerrett, M., Burnett, R. T., Kanaroglou, P., Eyles, J., Finkelstein, N., Giovis, C., \& Brook, J. R. (2001). A GIS environmental justice analysis of particulate air pollution in Hamilton, Canada. Environment and Planning, 33(6), 955-973. http://dx.doi.org/10.1068/a33137

Kaltenborn, B. P. (1998). Effects of sense of place on responses to environmental impacts: A study among residents in Svalbard in the Norwegian high Arctic. Applied Geography, 18(2), 169-189. http://dx.doi.org/10.1016/S0143-6228(98)00002-2

Lazarus, R. S., \& Folkman, S. (c1984). Stress, appraisal, and coping. New York: Springer Pub. Co.

Lovelock, B., Jellum, C., Thompson, A., \& Lovelock, K. (2013). Could immigrants care less about the environment? A comparison of the environmental values of immigrant and native-born New Zealanders. Society \& Natural Resources, 26(4), 402-419. http://dx.doi.org/10.1080/08941920.2012.697979

Mayo, S., \& Fraser, M. (2009). Incomes and poverty in Hamilton. Hamilton, ON: Social Planning \& Research Council of Hamilton.

Mayo, S., \& Pike, D. (2013). The rich and the rest of us. Hamilton, ON: Social Planning \& Research Council of Hamilton.

Meegan, R., \& Mitchell, A. (2001). 'It's Not Community Round Here, It's Neighbourhood': Neighbourhood Change and Cohesion in Urban Regeneration Policies. Urban Studies, 38(12), 2167-2194. http://dx.doi.org/10.1080/00420980120087117

Momsen, J. H. (2000). Gender differences in environmental concern and perception. Journal of Geography, 99(2), 47-56. http://dx.doi.org/10.1080/00221340008978956

Schultz, P. W., Unipan, J. B., \& Gamba, R. J. (2000). Acculturation and ecological worldview among Latino Americans. The Journal of Environmental Education, 31(2), 22-27. http://dx.doi.org/10.1080/00958960009598635

Shankardass, K. (2012). Place-based stress and chronic disease: A systems view of environmental determinants. In P. O'Camps, \& J. R. Dunn (Eds.), Rethinking social epidemiology: Towards a science of change (pp. 113-136) Springer Science \& Business. http://dx.doi.org/10.1007/978-94-007-2138-8_6

Statistics Canada. (2012). Hamilton, Ontario (Code 3525005) and Hamilton, Ontario (Code 3525) (table). Census Profile. 2011 Census. Statistics Canada Catalogue no. 98-316-XWE. Ottawa. Released May 29, 2012. http://www12.statcan.gc.ca/census-recensement/2011/dp-pd/prof/index.cfm?Lang=E. Accessed July 272012.

Stedman, R. (2003). Is it really just a social construction?: The contribution of the physical environment to sense of place. Society \& Natural Resources, 16(8), 671-685. http://dx.doi.org/10.1080/08941920309189

Stern, P. C., Dietz, T., \& Kalof, L. (1993). Value orientations, gender, and environmental concern. Environment and Behavior, 25(5), 322-348. http://dx.doi.org/10.1177/0013916593255002

Swan, J. (1970). Response to air pollution. Environment and Behavior, 2(2), 127-152. http://dx.doi.org/10.1177/001391657000200201

Vaske, J. J., \& Kobrin, K. C. (2001). Place attachment and environmentally responsible behavior. The Journal of Environmental Education, 32(4), 16-21. http://dx.doi.org/10.1080/00958960109598658

Vorkinn, M., \& Riese, H. (2001). Environmental concern in a local context the significance of place attachment. Environment and Behavior, 33(2), 249-263. http://dx.doi.org/10.1177/00139160121972972

Wakefield, S. E., Elliott, S. J., Cole, D. C., \& Eyles, J. D. (2001). Environmental risk and (re) action: Air quality, health, and civic involvement in an urban industrial neighbourhood. Health \& Place, 7(3), 163-177. http://dx.doi.org/10.1016/S1353-8292(01)00006-5

Williams, A., Kitchen, P., DeMiglio, L., Eyles, J., \& Newbold, B. (2010). Sense of place in Hamilton, Ontario: Empirical results of a neighbourhood-based survey. Urban Geography, 31(7), 905-931. http://dx.doi.org/10.2747/0272-3638.31.7.905

Williams, A., \& Kitchen, P. (2012). Sense of place and health in Hamilton, Ontario: A case study. Social Indicators Research, 108(2), 257-276. http://dx.doi.org/10.1007/s11205-012-0065-1

Wylie, J. (2009). Sense of place. In D. Gregory, R. Johnston, G. Pratt, M. J. Watts \& S. Whatmore (Eds.), The dictionary of human geography (5th ed., pp. 676). Chichester, UK: Wiley-Blackwell. 


\section{Appendix A: 16-item Sense of Place Scale (Williams et al. 2010) ${ }^{\mathrm{a}}$}

The following statements and questions have to do with your feelings about your neighbourhood.

For each, indicate the degree to which you agree or disagree.

D1. My neighbourhood means a great deal to me.

1 (Strongly agree) 2 (Agree) 3 (Neutral) 4 (Disagree) 5 (Strongly disagree)

D2. There's no other neighbourhood I would rather live.
1 (Strongly agree)
2 (Agree)
3 (Neutral)
4 (Disagree)
5 (Strongly disagree)

D3. I feel at home in my neighbourhood.
1 (Strongly agree)
2 (Agree)
3 (Neutral)
4 (Disagree)
5 (Strongly disagree)

D4. There are people in my neighbourhood who I think of as close friends.
1 (Strongly agree)
2 (Agree)
3 (Neutral)
4 (Disagree)
5 (Strongly disagree)

D5. I would like to stay in my neighbourhood as long as my health allows me to do so.
1 (Strongly agree)
2 (Agree)
3 (Neutral)
4 (Disagree)
5 (Strongly disagree)

D6. Green space availability in my neighbourhood positively influences my health.
1 (Strongly agree)
2 (Agree)
3 (Neutral)
4 (Disagree)
5 (Strongly disagree)

D7. Environmental problems in my neighbourhood (e.g. air pollution, run-down buildings) negatively influence my health.
1 (Strongly agree)
2 (Agree)
3 (Neutral)
4 (Disagree)
5 (Strongly disagree)

D8. Social problems in my neighbourhood (e.g. racism, violence) negatively influence my health.
1 (Strongly agree)
2 (Agree)
3 (Neutral)
4 (Disagree)
5 (Strongly disagree)

D9. The personal safety of myself and my family in my neighbourhood negatively affects my health
1 (Strongly agree)
2 (Agree)
3 (Neutral)
4 (Disagree)
5 (Strongly disagree)

How true are the following two statements?

D10. I know many of my neighbours on a first name basis.
1 (Very true)
2 (Fairly true)
3 (Neutral)
4 (Not very true)
5 (Not at all true)

D11. If I were to live somewhere else, it would be difficult to move away from my neighbourhood.
1 (Very true)
2 (Fairly true)
3 (Neutral)
4 (Not very true)
5 (Not at all true)

I would like to ask you several more questions on how you feel about your neighbourhood.

D13. How rooted do you feel in your neighbourhood?
1 (Very rooted)
2 (Fairly rooted)
3 (Neutral)
4 (Not very rooted)
5 (Not at all rooted)

D14. How connected do you feel to your neighbourhood?

1 (Very connected) $\quad 2$ (Fairly connected) $\quad 3$ (Neutral) $\quad 4$ (Not very connected) 5 (Not at all connected)

D15. How much do you like your neighbourhood?

1 (A great deal) $\quad 2$ (A fair amount) 3 (Neutral) 4 (Not very much) 5 (Not at all)

D16. How often do you participate in social activities with your neighbours (e.g barbeques, coffee dates, etc.)
1 (All the time)
2 (Often)
3 (Sometimes)
4 (Hardly ever)
5 (Never)

D17. If you had to leave your neighbourhood, how many of your neighbours would you miss?
1 (Many of them)
2 (Some of them)
3 (Neutral)
4 (Hardly any of them)
5 (None of them)

${ }^{\mathrm{a}}$ Factors

Neighbourhood rootedness $=$ D2+D13+D5+D11

Neighbourhood sentiment=D1+D3+D14+D15

Neighbours $=$ D10+D16+D4+D17

Environment and health=D6+D7+D8+D9

\section{(cc) $\mathrm{BY}$}

This work is licensed under a Creative Commons Attribution 3.0 License. 